\title{
An erythroid chaperone that facilitates folding of $\alpha$-globin subunits for hemoglobin synthesis
}

\author{
Xiang Yu, ${ }^{1}$ Yi Kong, ${ }^{2}$ Louis C. Dore, ${ }^{3}$ Osheiza Abdulmalik, ${ }^{3}$ Anne M. Katein,, ${ }^{4}$ Suiping Zhou, ${ }^{3}$ \\ John K. Choi, ${ }^{3}$ David Gell, ${ }^{5}$ Joel P. Mackay, ${ }^{5}$ Andrew J. Gow, ${ }^{6}$ and Mitchell J. Weiss ${ }^{3}$ \\ ${ }^{1}$ Cell and Molecular Biology Graduate Program, University of Pennsylvania School of Medicine, Philadelphia, Pennsylvania, USA. ${ }^{2}$ GlaxoSmithKline, \\ King of Prussia, Pennsylvania, USA. ${ }^{3}$ The Children's Hospital of Philadelphia, Philadelphia, Pennsylvania, USA. ${ }^{4}$ Safety Assessment, \\ AstraZeneca Pharmaceuticals LP, Wilmington, Delaware, USA. ${ }^{5}$ School of Molecular and Microbial Biosciences, University of Sydney, \\ New South Wales, Sydney, Australia. ${ }^{6}$ Department of Pharmacology, Rutgers University, Piscataway, New Jersey, USA.
}

\begin{abstract}
Erythrocyte precursors produce abundant $\alpha$ - and $\beta$-globin proteins, which assemble with each other to form hemoglobin A (HbA), the major blood oxygen carrier. $\alpha \mathrm{Hb}$-stabilizing protein (AHSP) binds free $\alpha$ subunits reversibly to maintain their structure and limit their ability to generate reactive oxygen species. Accordingly, loss of AHSP aggravates the toxicity of excessive free $\alpha$-globin caused by $\beta$-globin gene disruption in mice. Surprisingly, we found that AHSP also has important functions when free $\alpha$-globin is limited. Thus, compound mutants lacking both $A b s p$ and 1 of $4 \alpha$-globin genes (genotype $A b s p^{-/-\alpha-g l o b i n}{ }^{* \alpha / \alpha \alpha}$ ) exhibited more severe anemia and $\mathrm{Hb}$ instability than mice with either mutation alone. In vitro, recombinant AHSP promoted folding of newly translated $\alpha$-globin, enhanced its refolding after denaturation, and facilitated its incorporation into HbA. Moreover, in erythroid precursors, newly formed free $\alpha$-globin was destabilized by loss of AHSP. Therefore, in addition to its previously defined role in detoxification of excess $\alpha$-globin, AHSP also acts as a molecular chaperone to stabilize nascent $\alpha$-globin for $\mathrm{HbA}$ assembly. Our findings illustrate what we believe to be a novel adaptive mechanism by which a specialized cell coordinates high-level production of a multisubunit protein and protects against various synthetic imbalances.
\end{abstract}

\section{Introduction}

Hemoglobin A (HbA), the major blood oxygen carrier in adult mammals, is a heterotetramer of $\alpha$ - and $\beta$-globin proteins, each bound to heme $(1,2)$. Terminal erythropoiesis involves massive synthesis of $\mathrm{HbA}$, which constitutes roughly $95 \%$ of mature erythrocyte protein at a concentration of approximately $35 \mathrm{~g} / \mathrm{dl}$. Several biological and biophysical constraints can potentially interfere with this process. High protein concentrations within cells can cause misfolding and aggregation of newly synthesized polypeptides (3). Moreover, unassembled HbA components, including free $\alpha$-globin, $\beta$-globin, and heme, are inherently unstable and cytotoxic. An understanding of how $\mathrm{Hb}$ production is coordinated and controlled to maintain the stability of individual components, balance their synthesis, and optimize assembly has remained elusive in erythroid biology.

The biological effects of unbalanced HbA synthesis are illustrated by the thalassemia syndromes, a group of common inherited anemias in which mutations in either $\alpha$ - or $\beta$-globin genes (also known as $H B A$ and $H B B$, respectively) impair production of the corresponding protein, resulting in buildup of the unaffected subunit (4). In $\beta$ thalassemia, $\beta$-globin mutations cause $\alpha \mathrm{Hb}$ subunits to accumulate (5-8). Free $\alpha \mathrm{Hb}$ ( $\alpha$-globin plus heme, or holo- $\alpha$-globin) is a potent oxidant, catalyzing the production of ROSs, which damage erythroid precursors and mature erythrocytes (9). In addition, $\alpha \mathrm{Hb}$ is inherently unstable and tends to either precipitate, lodging in the cell membrane, or degrade, releasing toxic heme,

Nonstandard abbreviations used: AHSP, $\alpha \mathrm{Hb}$-stabilizing protein; CAE, cellulose acetate electrophoresis; $\mathrm{CD}$, circular dichroism; $\mathrm{GdCl}$, guanidinium chloride; $\mathrm{Hb}$, hemoglobin; TAU, triton-acetic acid-urea; TNT, transcription and translation. Conflict of interest: The authors have declared that no conflict of interest exists. Citation for this article: J. Clin. Invest. 117:1856-1865 (2007). doi:10.1172/JCI31664. porphyrins, iron, and apo- $\alpha$-globin polypeptide ( $\alpha$-globin without heme). Similar effects are observed in $\alpha$ thalassemia, where $\beta \mathrm{Hb}$ accumulates, precipitates, and damages cells. However, free $\alpha \mathrm{Hb}$ is more unstable than free $\beta \mathrm{Hb}$, in part because free $\alpha \mathrm{Hb}$ exists predominantly as monomers, while free $\beta \mathrm{Hb}$ tends to self-associate into homo-tetramers, which imparts some stability (10).

Several observations indicate that erythroid cells contain adaptive mechanisms to stabilize free $\alpha \mathrm{Hb}$ and limit its toxicity. First, erythroid precursors contain a small pool of excess free $\alpha \mathrm{Hb}$, with no deleterious effects $(11,12)$. Second, individuals with the $\beta$ thalassemia trait, who lack approximately $50 \% \beta$-globin gene output, are well compensated, with minimal erythroid pathologies (13). In general, cells cope with potentially damaging unstable proteins through 2 interrelated mechanisms (reviewed in refs. 3, 14, and 15). First, proteolytic systems recognize and eliminate misfolded and/or potentially toxic proteins. Accordingly, pathways to degrade excess free $\alpha \mathrm{Hb}$ occur in erythroid cells, although the molecular mechanisms are not well defined (16-18). Second, most cells contain molecular chaperones that bind, stabilize, and fold potentially toxic protein intermediates during their normal synthesis or upon pathologic accumulation. Recently, we discovered $\alpha \mathrm{Hb}$-stabilizing protein (AHSP, also called erythroid-associated factor [ERAF] and erythroid differentiation-related factor [EDRF]), a small, abundant erythroid protein that binds multiple forms of $\alpha$-globin, stabilizes their structures, and limits their prooxidant activities (19).

In vitro studies using purified proteins showed that AHSP binds $\alpha \mathrm{Hb}$, but not $\beta \mathrm{Hb}$ or $\operatorname{HbA}(19,20)$. In agreement with this finding, crystallographic analysis revealed that AHSP and $\beta \mathrm{Hb}$ have overlapping binding sites on $\alpha \mathrm{Hb}(21)$. Moreover, $\beta \mathrm{Hb}$ binds $\alpha \mathrm{Hb}$ much more tightly than AHSP. Therefore, under normal physiological concentrations of $\beta \mathrm{Hb}, \mathrm{AHSP}$ is not expected to interfere with $\mathrm{HbA}$ 


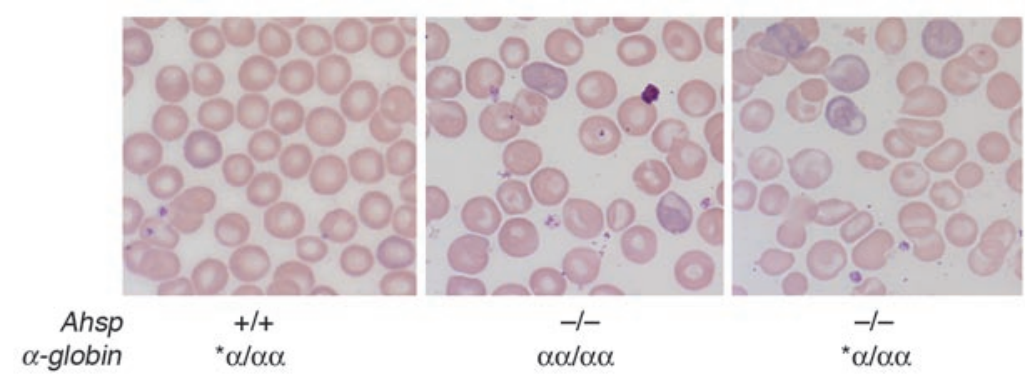

\section{Figure 1}

Abnormal erythrocyte morphology in $\mathrm{Ahsp}^{-/-} \alpha-$ globin ${ }^{\star \alpha / \alpha \alpha}$ double-mutant mice. Wright-Giemsa staining of peripheral blood from mice with genotypes indicated. Note that variations in erythrocyte size and shape are more severe in the compound Ahsp- $\alpha$-globin mutants (far right panel). Original magnification, $\times 200$. synthesis or function. In vitro, recombinant AHSP reduces ROS production by purified $\alpha \mathrm{Hb}$, increases its thermostability, and inhibits its precipitation $(19,21,22)$. Ahs $p^{-/-}$mice exhibit hemolytic anemia with increased levels of erythroid ROS and $\mathrm{Hb}$ precipitates, demonstrating an essential role in Hb homeostasis (22). Loss of AHSP also exacerbates anemia and $\mathrm{Hb}$ precipitation in a murine model of $\beta$ thalassemia (22). Together, these studies indicate that AHSP detoxifies excess $\alpha \mathrm{Hb}$ that accumulates to low levels in normal erythroid cells and to a much greater extent in $\beta$ thalassemia $(8,12)$. A mechanism for this function is provided by biochemical and structural studies showing that AHSP converts ferrous (FeII) oxygenated $\alpha \mathrm{Hb}$ to a more stable ferric (FeIII) bis-histidyl form $(21,23)$.

We reasoned that if inhibiting the toxicities of excessive free $\alpha \mathrm{Hb}$ is the major role for AHSP, then it should be possible to alleviate the $A h s p^{-/-}$phenotype by reducing $\alpha$-globin gene dosage. To test this, we generated $A b s p^{-/-}$mice that also lack 1 of $4 \alpha$-globin alleles (genotype $\alpha$-globin ${ }^{*} \alpha / \alpha \alpha$, also known as $\mathrm{Hba}$ ). By itself, this $\alpha$-globin mutation, termed $\alpha$ thalassemia silent carrier state, causes

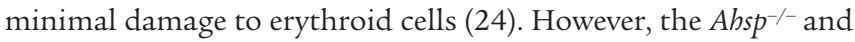
$\alpha$-globin ${ }^{*} \alpha / \alpha \alpha$ mutations combined cause erythroid abnormalities that are substantially more severe than those resulting from either mutation alone. Most notably, both $\alpha$-globin and $\beta$-globin were destabilized, even though AHSP does not bind the latter. Failure of reduced $\alpha$-globin gene dosage to suppress the $A h s p^{-/-}$phenotype might indicate that AHSP not only acts to neutralize excessive $\alpha \mathrm{Hb}$, but also promotes the stability of nascent $\alpha$ chains for subsequent incorporation into $\mathrm{HbA}$. In this case, loss of viable $\alpha$-globin in $A b s p^{-/-} \alpha$-globin ${ }^{*} \alpha / \alpha \alpha$ mice would increase the level of free $\beta$-globin, thus promoting its precipitation. In support of this model, we show that AHSP promotes native folding of apo- $\alpha$-globin and its assembly into $\alpha \mathrm{Hb}$ in solution and stabilizes a pool of free $\alpha \mathrm{Hb}$ in erythroid precursors. Together, these studies identify AHSP as a tissue-specific molecular chaperone that protects erythroid cells from various stresses and imbalances related to HbA synthesis.

\section{Results}

The $\alpha$ thalassemia silent carrier state exacerbates loss of AHSP. Previous genetic and biochemical studies indicated that AHSP protects cells from the deleterious effects of excess free $\alpha \mathrm{Hb}$ (21-23). In this case, reducing free $\alpha$-globin levels might alleviate $\mathrm{Hb}$ instability and ane-

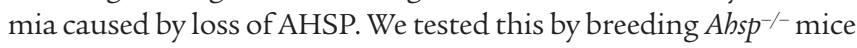
to the $\alpha$ thalassemia silent carrier strain, termed $\alpha$-globin ${ }^{*} \alpha / \alpha \alpha$, which lacks 1 of $4 \alpha$-globin genes and exhibits minimal erythroid abnormalities (24). Most notably, compound mutant mice (genotype $A h s p^{-/-\alpha}$-globin $\left.{ }^{*} \alpha / \alpha \alpha\right)$ exhibited more severe erythroid pathologies than mice with either mutation alone. Erythrocyte morphologies of the mutant mice are shown in Figure 1. Loss of $1 \alpha$-globin allele had no apparent effects (left panel), while $A b s p^{-/-}$erythrocytes exhibited irregularities in shape, with eosinophilic inclusions in some cells, as reported previously (22) (middle panel). In contrast, the double-mutant erythrocytes had increased central pallor and more pronounced variations in size and shape (right panel). Automated hematology analysis confirmed these differences quantitatively and demonstrated that the double-mutant animals were about $10 \%$ more anemic than $A b s p^{-/-}$mice (Table 1). In summary, the erythroid abnormalities imparted by loss of AHSP were greater in mice that had lost $1 \alpha$-globin allele, as evidenced by examination of cell morphologies and erythrocyte indices. This was somewhat surprising, as we initially expected that the ${ }^{*} \alpha / \alpha \alpha$ genotype might alleviate the effects of AHSP loss by reducing the level of toxic free $\alpha$-globin.

The erythroid abnormalities in $A b s p^{-/-} \alpha-g l o b i{ }^{*} \alpha / \alpha \alpha$ mice suggest that the combined mutations intensify $\mathrm{Hb}$ instability. Unstable $\mathrm{Hbs}$

\section{Table 1}

Erythroid indices of $A h s p$ and $\alpha$-globin mutant mice

\begin{tabular}{|c|c|c|c|c|c|c|}
\hline Ahsp & + & & & & & \\
\hline$\alpha$-Globin & $\alpha \alpha / \alpha \alpha(n=17)$ & ${ }^{*} \alpha / \alpha \alpha(n=18)$ & $\alpha \alpha / \alpha \alpha(n=14)$ & ${ }^{*} \alpha / \alpha \alpha(n=25)$ & Column 2 vs. 4 & Column 3 vs. 4 \\
\hline $\mathrm{Hb}(\mathrm{g} / \mathrm{dl})$ & $16.3 \pm 0.4$ & $15.3 \pm 0.9$ & $14.7 \pm 1.3$ & $13.4 \pm 1.0$ & $<0.0001$ & 0.001 \\
\hline Hct (\%) & $53.1 \pm 1.7$ & $51.1 \pm 2.5$ & $48.0 \pm 3.2$ & $42.5 \pm 3.6$ & $<0.0001$ & $<0.0001$ \\
\hline Reticulocytes (\%) & $2.7 \pm 0.5$ & $3.6 \pm 0.8$ & $5.3 \pm 1.1$ & $7.2 \pm 2.7$ & $<0.0001$ & 0.0017 \\
\hline $\operatorname{MCV}(f l)$ & $51.8 \pm 2.0$ & $48.0 \pm 1.6$ & $46.8 \pm 1.8$ & $42.6 \pm 2.2$ & $<0.0001$ & $<0.0001$ \\
\hline $\mathrm{MCH}(\mathrm{pg})$ & $15.8 \pm 0.4$ & $14.4 \pm 0.5$ & $14.2 \pm 0.5$ & $13.4 \pm 0.8$ & $<0.0001$ & 0.002 \\
\hline RDW (\%) & $12.7 \pm 0.8$ & $18.0 \pm 1.4$ & $18.8 \pm 1.7$ & $25.2 \pm 1.9$ & $<0.0001$ & $<0.0001$ \\
\hline HDW (g/dl) & $1.7 \pm 0.2$ & $2.2 \pm 0.2$ & $2.4 \pm 0.2$ & $3.1 \pm 0.3$ & $<0.0001$ & $<0.0001$ \\
\hline
\end{tabular}

Values represent mean \pm SD. $n$ refers to numbers of mice analyzed. Student's $t$ test was performed to analyze $P$ values for differences between the indicated genotypes. Hct, hematocrit; $\mathrm{HDW}, \mathrm{Hb}$ distribution width (reflects $\mathrm{MCH}$ variation); $\mathrm{MCH}$, mean corpuscular $\mathrm{Hb}$; MCV, mean corpuscular volume; RDW, red cell distribution width (reflects size variation). 


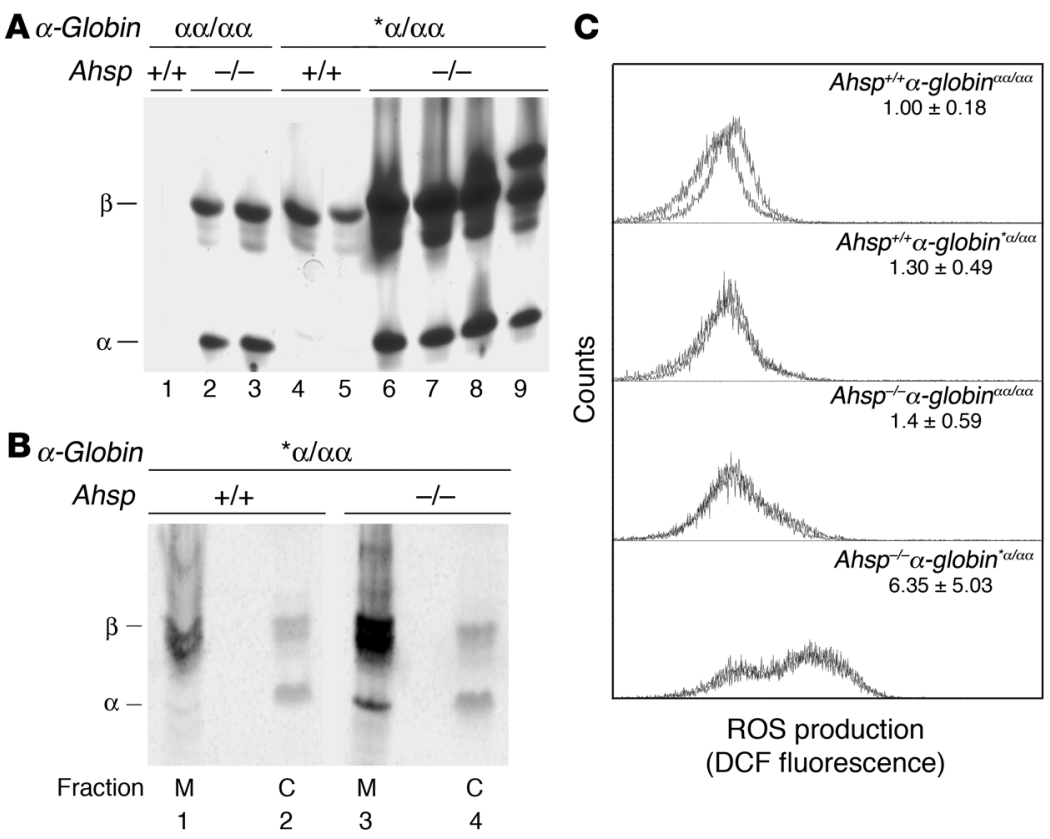

Figure 2

Increased $\mathrm{Hb}$ instability in $A h s p^{-/} \alpha-g / o b i{ }^{*} \alpha / \alpha \alpha$ double-mutant erythrocytes. (A) Steadystate membrane-associated $\mathrm{Hbs}$. TAU gel analysis of membrane skeletons prepared from equal numbers of erythrocytes from mice with genotypes indicated. $\alpha$ - and $\beta$-globin chains were stained with Coomassie blue and are indicated. Lane 9 represents an altered $\beta$-globin genotype, which results in 2 bands. (B) Analysis of newly synthesized globin chains. Equal numbers of reticulocytes were pulse-labeled with ${ }^{35} \mathrm{~S}$-methionine and ${ }^{35} \mathrm{~S}$-cysteine for 15 minutes, then disrupted by hypotonic lysis. Ahsp and $\alpha$-globin genotypes are indicated. Soluble cytoplasmic (C) and membrane-associated (M) globins were isolated by differential centrifugation, fractionated on TAU gels, and visualized by autoradiography. The data shown derive from mice with the diffuse $\beta$-globin genotype. Results of quantitative analysis of nascent globins in membrane and cytoplasmic fractions from multiple experiments are shown in Table 2. (C) Quantification of ROS. Erythrocytes were incubated with dichlorofluorescin diacetate (DCFH-DA), which enters cells and is converted by ROS to the fluorescent product DCF. Representative flow cytometry data from 2 mice of each genotype are shown. Data from all mice analyzed are summarized in the upper-right corner of each panel, which shows the mean fluorescent intensity of DCF signal with wild-type erythrocytes normalized to 1.0. Three to 6 mice from each group were analyzed.

tend to precipitate and lodge in the erythrocyte plasma membrane (25-30). We collected equal numbers of erythrocytes from mice with various genotypes, prepared membrane fractions, and analyzed bound globins by Triton-acetic acid-urea (TAU) gel electrophoresis, which resolves $\alpha$ and $\beta$-globin subunits under denaturing conditions (Figure 2A). Wild-type erythrocytes contained no detectable membrane-associated globins, reflecting optimal chain balance and stability (lane 1). Loss of AHSP alone caused precipitation of both $\alpha$ - and $\beta$-globin at roughly equal ratios, as reported previously (22) (genotype $A h s p^{-1}$, lanes 2 and 3 ), while the $\alpha$ thalassemia silent carrier state was associated with low-level $\beta$-globin precipitates, reflecting mild $\alpha$-globin deficiency (genotype $\alpha$-globin ${ }^{*} \alpha / \alpha$, , lanes 4 and 5). Importantly, precipitation of both globins, particularly the $\beta$ subunit, was increased in the double-mutant mice (genotype Absp ${ }^{-/-} \alpha-g l o b i n^{*} \alpha / \alpha \alpha$, lanes 6-9). This confirms and extends our previous findings that loss of AHSP destabilizes $\beta$-globin in vivo (22), likely through indirect effects, since AHSP does not bind $\beta$-globin directly (19).

Analysis of steady-state membrane-associated globin chains (Figure 2A) showed that in the context of $\alpha$ thalassemia silent carrier state, loss of AHSP destabilizes $\alpha$-globin and, to a greater extent, $\beta$-globin. To investigate this more quantitatively and assess the kinetics of globin precipitation, we pulse-labeled equal numbers of reticulocytes from $\alpha$-globin ${ }^{* \alpha / \alpha \alpha}$ and Absp $p^{-/-} \alpha$-globin ${ }^{*} \alpha / \alpha \alpha$ mice with ${ }^{35} \mathrm{~S}$-methionine and ${ }^{35} \mathrm{~S}$-cysteine for 15 minutes and analyzed nascent globins in cytoplasmic and membrane fractions by TAU gel electrophoresis and autoradiography. We quantified the proportions of $\alpha$-and $\beta$-globins in the cytosol and plasma membrane by Phosphorimager analysis. An example of the TAU gel is shown in Figure 2B, and quantitative analysis of globin chain distributions in reticulocytes from multiple animals is summarized in Table 2. In the $\alpha$ thalassemia silent carrier state, approximately $25 \%$ of nascent $\beta$-globin chain precipitated into the membrane (Figure 2B, lane 1, and Table 2); this was increased to approximately $45 \%$ by concomitant loss of AHSP (Figure 2B, lane 3, and Table 2 ). In addition, approximately $11 \%$ of nascent $\alpha$-globin precipitated in $\alpha$ thalassemia mice lacking AHSP. These findings are consistent with analysis of steady-state globin precipitates (Figure 2A) and further show that pathological globin precipitation occurs rapidly in the mutant animals.

Loss of AHSP could enhance the accumulation of unstable $\beta$-globin chains by inhibiting $\alpha$-globin synthesis. To investigate this possibility, we quantified total (membrane plus cytosolic) ${ }^{35}$ S-labeled globins synthesized after pulse-labeling by Phosphorimager analysis of TAU gels. In single-mutant $\alpha$-globin ${ }^{*} \alpha / \alpha \alpha$ reticulocytes, the $\alpha / \beta$ synthetic ratio was approximately 0.76 , consistent with loss of a single $\alpha$-globin allele. This ratio was not significantly different in $A b s p^{-/-} \alpha$-globin ${ }^{*} \alpha / \alpha \alpha$ double mutants (Table 2). Hence, in the $\alpha$ thalassemia silent carrier state, loss of AHSP increases both $\alpha$-and $\beta$-globin precipitation without affecting the $\alpha / \beta$-globin chain synthetic ratio. Most likely, in the double-mutant mice, rapid precipitation of newly synthesized $\alpha$-globin caused by loss of AHSP aggravates $\alpha$ thalassemia by increasing the level of free $\beta$-globin, thereby enhancing its precipitation. This effect may also be accelerated by ROS produced by unstable free $\alpha$-globin (21). It is also theoretically possible that

\section{Table 2}

Synthesis and fate of nascent globin chains in reticulocytes

\begin{tabular}{lcc}
$\alpha$-Globin & \multicolumn{2}{c}{${ }^{*} \alpha / \alpha \alpha$} \\
Ahsp & $+/+$ & $-/-$ \\
Mice analyzed & 4 & 5 \\
Total $\alpha / \beta$-globin synthesis & $0.76 \pm 0.02$ & $0.70 \pm 0.06$ \\
Cytosolic $\alpha / \beta$-globin & $1.02 \pm 0.12$ & $1.14 \pm 0.12$ \\
$\alpha$-Globin, membrane/total & $<2 \%$ & $11 \% \pm 3 \%$ \\
$\beta$-Globin, membrane/total & $25 \% \pm 9 \%$ & $45 \% \pm 8 \%$
\end{tabular}

Reticulocytes were radiolabeled for 15 minutes. Globin chain synthetic ratios and their subcellular distributions were determined as described for Figure 2B and in Methods. 

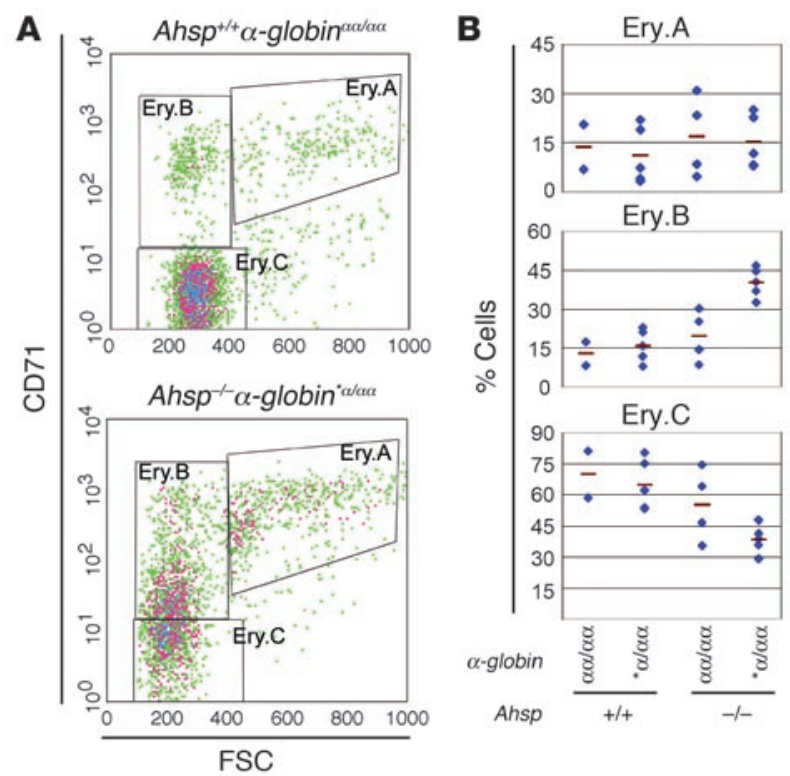

AHSP stabilizes newly synthesized $\beta$-globin directly, although this is unlikely, as AHSP does not bind or stabilize purified $\beta$-globin (ref. 19 and data not shown).

Free $\mathrm{Hb}$ subunits and their breakdown products catalyze the production of ROS, causing secondary damage to cellular proteins and lipids (9). We measured ROS in erythrocytes using the dye dichlorofluorescin diacetate (DCFH-DA), which enters cells and is converted to the fluorescent product DCF upon oxidation (Figure 2C). Separately, $A b s p^{-/-}$and $\alpha$-globin ${ }^{*} \alpha / \alpha \alpha$ erythrocytes both contained mildly increased ROS levels. However, ROS levels increased about 4-fold in the double mutants. This indicates further that the 2 mutations synergize to cause $\mathrm{Hb}$ instability.

Unstable Hbs can impair the maturation and viability of erythroid precursors in a process termed ineffective erythropoiesis (8). We used a quantitative flow cytometry-based assay to distinguish different developmental stages in cells expressing the erythroidspecific antigen Ter119 (Figure 3) (31). This approach uses CD71 (transferrin receptor) expression and forward scatter (FSC) to distinguish 3 different Ter $119^{+}$erythroid precursors, termed Ery.A, Ery.B, and Ery.C, which represent progressive stages of maturation (Figure 3A). In $A b s p^{-/-} \alpha$-globin ${ }^{*} \alpha / \alpha \alpha$ mice, there was altered erythroid precursor distribution with reduced transition from Ery.B to Ery.C (Figure 3A, compare upper and lower panels). This effect was verified in multiple animals (Figure 3B) and suggests impaired maturation of $A b s p^{-/-} \alpha-g l o b i n{ }^{*} \alpha / \alpha \alpha$ erythroid precursors at a stage coincident with high-level $\mathrm{Hb}$ synthesis. A similar effect of less magnitude was suggested in $A b s p^{-/-}$mice (Figure 3B). Hence, loss of AHSP and $1 \alpha$-globin gene together impair erythroid development to a greater extent than either mutation individually. Most likely, this abnormality is due to the damaging effects of unstable $\mathrm{Hbs}$ on the maturation and/or survival of erythroid precursors.

AHSP promotes $H b A$ assembly from newly synthesized $\alpha$-globin in vitro. Our genetic studies demonstrate that AHSP is important for $\mathrm{Hb}$ stability and erythropoiesis even when $\alpha$-globin is not present in excess. A likely explanation for the more severe erythroid phenotype of $A b s p^{-/-}$and $\alpha$-globin ${ }^{*} \alpha / \alpha \alpha$ double mutants is that AHSP specifically stabilizes newly synthesized $\alpha$-globin to augment its incorporation into $\mathrm{HbA}$. In this scenario, loss of AHSP causes pre-

\section{Figure 3}

Blocked erythroid maturation in double-mutant mice. (A) The developmental stage of splenic erythroid precursors was analyzed by flow cytometry according to a protocol described by Liu et al (31). Ter119+ erythroid progenitors were fractionated by forward scattering and CD71 expression into increasingly mature populations, termed Ery.A, Ery.B, and Ery.C. Results of representative experiments on wild-type and double-mutant mice are shown. (B) Two to 5 mice of each genotype were analyzed at age 6 months. The $y$ axis shows frequencies of spleen erythroblast subsets as percentage of total Ter119+ cells for each genotype indicated on the $x$ axis. Each symbol represents data for a single mouse. The horizontal bar indicates the mean value. The differences between single and double mutants were statistically significant (2-tailed $P$ value): Ery.B: Ahs $p^{-/-}$versus $A h s P^{-/-} \alpha$-globin ${ }^{*} \alpha / \alpha \alpha$, $P<0.005 ; \alpha-g l o b i n^{*} \alpha / \alpha \alpha$ versus Ahsp ${ }^{-/} \alpha-g l o b i n^{*} \alpha / \alpha \alpha, P<0.001$; Ery.C: Ahsp ${ }^{-/-}$versus $A h s p^{-/-} \alpha-$ globin ${ }^{*} \alpha / \alpha \alpha, P<0.08 ; \alpha-g l o b i n^{*} \alpha / \alpha \alpha$ versus Ahsp $^{-/-\alpha-g l o b i n}{ }^{*} \alpha / \alpha, \alpha, P<0.003$.

cipitation of nascent $\alpha$-globin, exacerbating $\beta$-globin excess in the setting of mild $\alpha$ thalassemia.

We examined this possibility further by studying how purified recombinant AHSP affects $\mathrm{HbA}$ formation from $\alpha \mathrm{Hb}$ synthesized in vitro. First, we used a wheat germ-derived transcription and translation (TNT) reaction to generate $\alpha \mathrm{Hb}$ from its cDNA (Figure $4 \mathrm{~A}$ ). We used the wheat germ system because AHSP is absent, in contrast to TNT systems derived from reticulocyte lysates. Radiolabeled $\alpha$-globin protein was synthesized in the presence of cyano-hemin (a stable form of heme), with or without added recombinant AHSP. Then, purified, unlabeled $\beta \mathrm{Hb}$ was added and HbA formation was analyzed by cellulose acetate electrophoresis (CAE), a nondenaturing method that fractionates mainly according to charge. Incorporation of newly synthesized $\alpha$-globin into $\mathrm{HbA}$ was assessed by autoradiography of the CAE membrane. We also measured total $\alpha$-globin polypeptide synthesis by denaturing SDS-PAGE and autoradiography. Addition of recombinant AHSP augmented HbA formation from nascent $\alpha \mathrm{Hb}$ in a dosedependent fashion (Figure 4B, CAE), without affecting the overall yield of full-length $\alpha$-globin polypeptide (Figure 4B, SDS-PAGE). Moreover, HbA production was augmented most effectively when recombinant AHSP was present during the entire course of the TNT reaction, indicating that AHSP stabilizes apo- $\alpha$-globin and/ or $\alpha \mathrm{Hb}$ cotranslationally or immediately afterward (Figure 4C). AHSP containing a point mutation (D43R) that inhibits binding to $\alpha \mathrm{Hb}$ had no effect on HbA synthesis from nascent $\alpha \mathrm{Hb}$ (Figure 4D). In addition, AHSP had no effect on the incorporation of newly synthesized TNT-derived $\beta \mathrm{Hb}$ into HbA (data not shown). Together, these findings indicate that AHSP specifically maintains newly synthesized $\alpha \mathrm{Hb}$ in a soluble state that is competent for assembly with $\beta \mathrm{Hb}$ to form $\mathrm{HbA}$.

AHSP promotes native folding of nascent apo- $\alpha$-globin. Previously, we showed that AHSP binds purified apo- $\alpha$-globin (32). We therefore asked whether AHSP stabilizes newly synthesized apo- $\alpha$-globin prior to heme insertion and $\mathrm{HbA}$ assembly. To test this, we exploited the principle that native folded proteins are relatively resistant to proteolysis compared with their unfolded counterparts $(33,34)$. We synthesized radiolabeled $\alpha$-globin with or without recombinant 


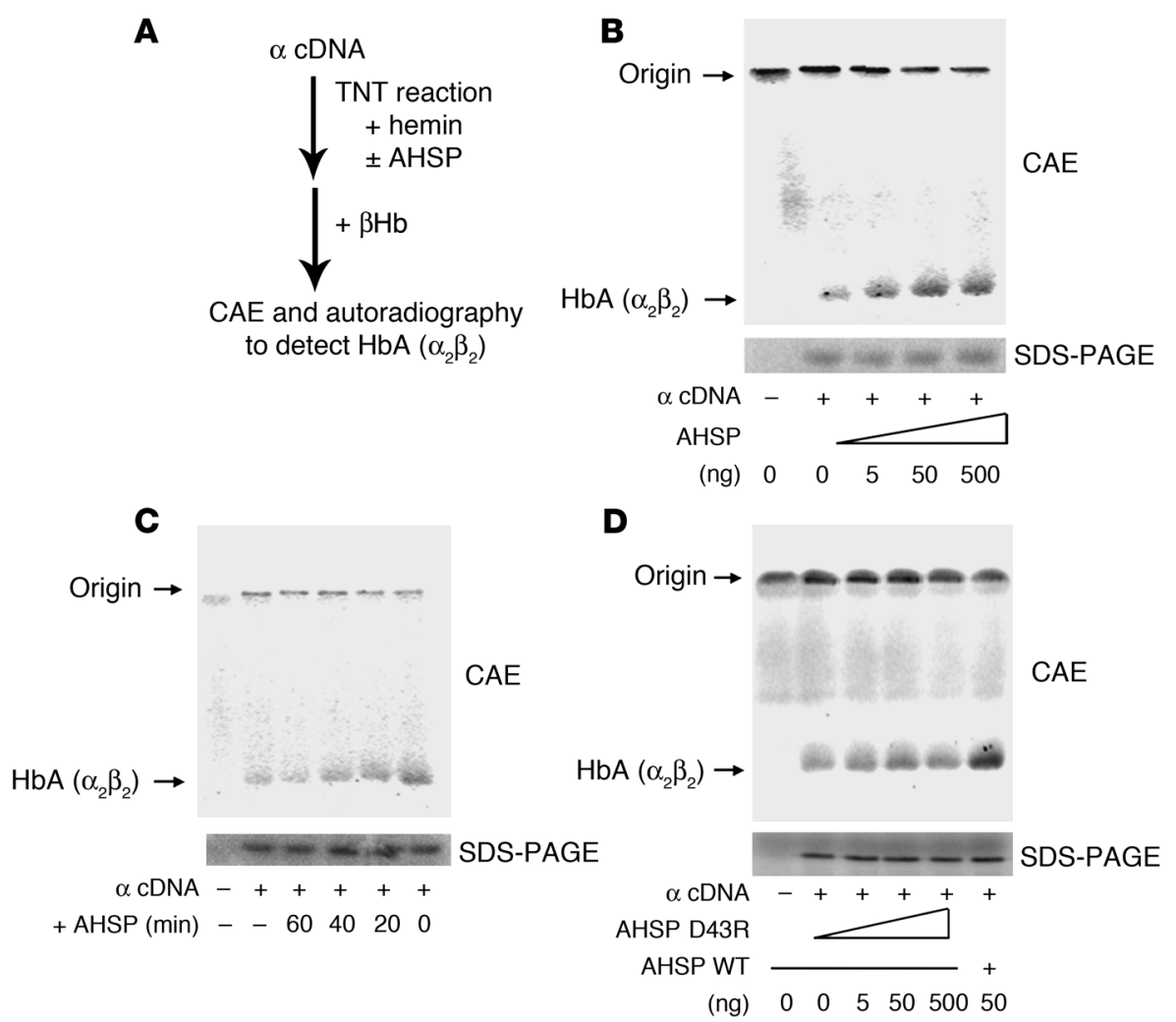

\section{Figure 4}

AHSP stabilizes newly synthesized $\alpha$-globin in vitro. (A) Experimental approach. $\alpha$-Globin was synthesized in a wheat germ-based TNT system containing ${ }^{35} \mathrm{~S}$-methionine and heme, with or without purified recombinant AHSP protein added. Then, cold $\beta \mathrm{Hb}$ was added, and $\mathrm{HbA}$ tetramer $\left(\alpha_{2} \beta_{2}\right)$ formation was assessed by CAE and autoradiography. $\alpha$ cDNA, $\alpha$-globin cDNA. (B) Dose-response effects of added AHSP on subsequent $\mathrm{HbA}$ formation from newly synthesized $\alpha$-globin. (C) Effect of varying the time of addition of recombinant AHSP (50 ng) to the $\alpha$-globin TNT reaction. AHSP was added at $0,20,40$, or 60 minutes after initiation of ${ }^{35} \mathrm{~S}$-labeled $\alpha$-globin synthesis. At $60 \mathrm{~min}-$ utes, purified $\beta \mathrm{Hb}$ was added and formation of $\mathrm{HbA}$ examined by CAE. $\alpha$-Globin was most effectively utilized for $\mathrm{HbA}$ formation when AHSP was present at the beginning of the TNT reaction. (D) ${ }^{35}$ S-labeled $\alpha$-globin was synthesized with added AHSP D43R, a reduced-affinity $\alpha$-globin-binding mutant. In contrast to wildtype AHSP, the D43R mutant does not augment formation of $\mathrm{HbA}$ from of TNTderived $\alpha$-globin.
AHSP in the wheat germ TNT system without added heme. Next, we treated the product with trypsin and tested the extent of digestion by SDS-PAGE and autoradiography (Figure 5, A-D). Wild-type AHSP protected nascent $\alpha$-globin from proteolytic digestion (Figure 5A, compare first and second panels; Figure 5B). This effect is not simply because AHSP physically inhibits access to protease, as most predicted trypsin cleavage sites on $\alpha$-globin are outside of the AHSP binding surface (Supplemental Figure 1; supplemental material available online with this article; doi:10.1172/JCI31664DS1). More likely, AHSP causes $\alpha$-globin to become protease resistant by promoting proper folding into a native state.

Addition of hemin during the TNT reaction also conferred protease resistance to nascent $\alpha$-globin (Figure 5A compare left and right panels; Figure 5B), consistent with previous findings that heme stabilizes $\alpha$-globin folding (35-37). The mutant AHSP D43R, which binds $\alpha$-globin at reduced affinity (21), did not protect nascent $\alpha$-globin from proteolytic digestion (Figure 5, C and D). Together, these results demonstrate that AHSP promotes and/ or stabilizes apo- $\alpha$-globin folding independent of heme.

AHSP promotes refolding of denatured $\alpha$-globin. The ability of AHSP to promote folding of nascent $\alpha$-globin and its assembly into $\mathrm{HbA}$ is consistent with the function of a molecular chaperone. Some chaperones also promote refolding of their client proteins after denaturation. We tested whether this is true for AHSP and apo$\alpha$-globin. Apo- $\alpha$-globin was denatured in phosphate buffer $\mathrm{pH} 7.0$ with $0.5 \mathrm{M}$ guanidinium chloride $(\mathrm{GdCl})$, mixed with a 1.8 -fold molar excess of purified recombinant AHSP, and analyzed for secondary structure by circular dichroism (CD) spectropolarimetry (Figure 5, E and F). Under these conditions, apo- $\alpha$-globin showed minimal helical content, while AHSP retained its native helical structure (Supplemental Figure 2, B and C). Importantly, when apo- $\alpha$-globin was mixed with AHSP, the measured CD spectrum revealed helical content that was significantly greater than the theoretical sum of the CD spectra of the 2 components examined separately (Figure 5E, double arrow, and Figure 5F, solid line). This effect was not observed with the reduced $\alpha$-globin affinity mutant AHSP D43R (Figure 5F and Supplemental Figure 2E). The most likely interpretation is that AHSP promotes refolding of denatured apo- $\alpha$-globin. Alternatively, AHSP might gain additional secondary structure after binding apo- $\alpha$-globin. However, this is less likely for 2 reasons. First, AHSP mixed with native ("holo") $\alpha \mathrm{Hb}$ produced a CD spectrum nearly identical to the calculated sum of the individual spectra, indicating no net change in helicity upon formation of the $\alpha \mathrm{Hb}$-AHSP complex (Figure 5F and Supplemental Figure 2F). Second, NMR and x-ray crystallographic studies indicate no appreciable changes in the $\alpha$-helical content of AHSP upon binding to $\alpha \mathrm{Hb}(21,38)$ (data not shown).

AHSP stabilizes a pool of nascent $\alpha$-globin in erythroid cells. To identify $\alpha \mathrm{Hb}$-AHSP complexes in vivo, we pulse-labeled reticulocytes with ${ }^{35} \mathrm{~S}$-methionine and analyzed soluble cytoplasmic fractions by isoelectric focusing under conditions that resolve different $\mathrm{Hb}$ complexes. For these experiments, we used mice with $\beta$ thalassemia (genotype $\beta$-globin ${ }^{+/ t h-3}$ to favor detection of non-HbAassociated $\alpha \mathrm{Hb}(39)$.

The only protein detected at steady state was $\mathrm{HbA}$, as evidenced by a single band in the unstained gel (Figure 6, bottom). However, autoradiography to visualize nascent proteins revealed 3 additional prominent bands (Figure 6, top, lane 1). The identity of the most slowly migrating band, labeled with an asterisk, is unknown. Based on our previous studies of recombinant proteins, we predicted that the other 2 bands represent free $\alpha \mathrm{Hb}$ and $\alpha \mathrm{Hb}$-AHSP, labeled accordingly (19). In agreement with 
A

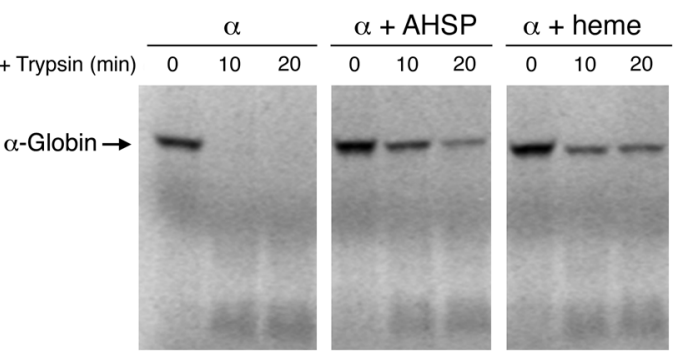

C
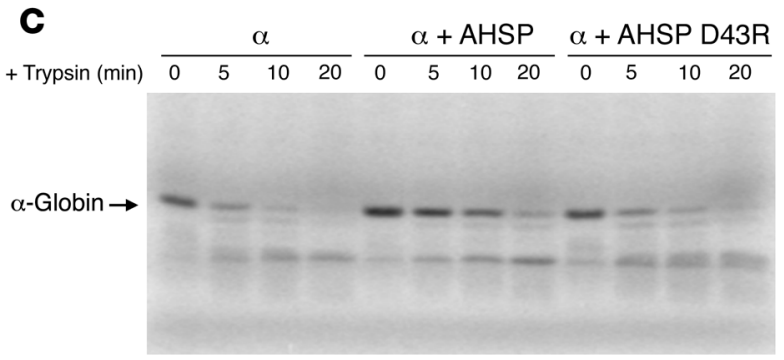

$\mathbf{E}$

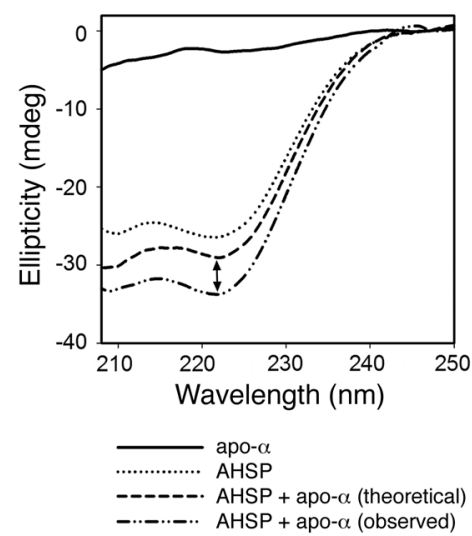

B

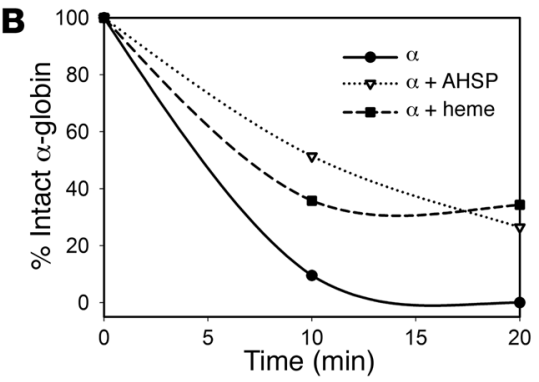

D

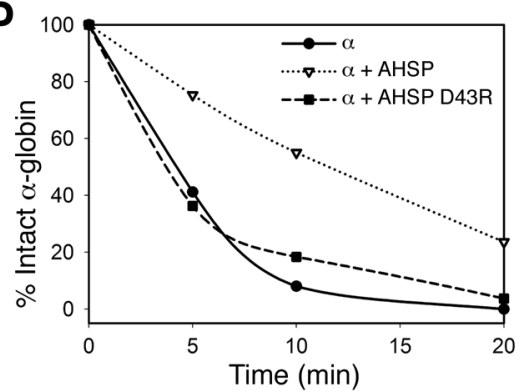

$\mathbf{F}$

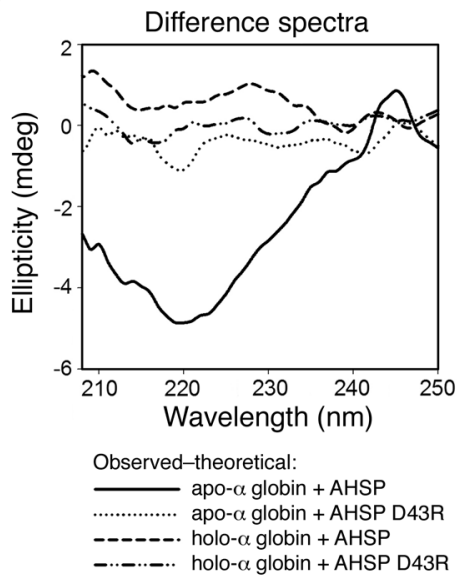

Figure 5

AHSP facilitates $\alpha$-globin folding. (A) AHSP confers protease resistance to nascent apo- $\alpha$-globin. ${ }^{35}$ S-radiolabeled $\alpha$-globin was synthesized by TNT using wheat germ extract with or without $4 \mu \mathrm{g} / \mathrm{ml}$ recombinant AHSP or $\mathrm{CN}$-hemin $(0.2 \mu \mathrm{M})$, then treated with $10 \mu \mathrm{g} / \mathrm{ml}$ trypsin for the indicated times. Polypeptides were fractionated on SDS-PAGE gels and visualized by autoradiography. (B) Quantitative analysis of signal intensities for fulllength $\alpha$-globin from the experiment represented in A. (C) Reduced $\alpha$-globin-binding mutant AHSP D43R fails to confer protease resistance to nascent a-globin. The experiment was performed as described for Figure 5A. (D) Quantitative analysis of signal intensities for full-length $\alpha$-globin from the experiment represented in C. (E) AHSP promotes refolding of denatured apo- $\alpha$-globin. Denatured apo- $\alpha$-globin $(5 \mu \mathrm{M})$ and purified recombinant AHSP $(9 \mu \mathrm{M})$ were analyzed for $\alpha$-helical content by CD separately and then mixed together, incubated for 30 minutes at $4^{\circ} \mathrm{C}$, and reanalyzed. Helical content is indicated by a negative peak in the ellipticity signal at $222 \mathrm{~nm}$. Note that the measured helical content of the AHSP plus apo- $\alpha$-globin mixture (labeled "observed") exceeds the calculated theoretical sum of the helical content of AHSP and apo- $\alpha$-globin measured separately. (F) Difference spectra (observed - theoretical CD spectra) for various $\alpha$-globin-AHSP mixtures. The spectra shown are derived from B and from Supplemental Figure 2, E and F.

these assignments, addition of excess purified human $\beta \mathrm{Hb}$ drove both bands into a faster-moving species that migrated at the position of murine $\alpha \mathrm{Hb} /$ human $\beta \mathrm{Hb}$ heterotetramers $\left(m \alpha_{2} \mathrm{~h} \beta_{2}\right.$, lane 2). Also, addition of purified recombinant murine AHSP drove free $\alpha \mathrm{Hb}$ into the presumed $\alpha \mathrm{Hb}$-AHSP complex (lane 3 ). We obtained similar results in Absp ${ }^{+/-}$heterozygotes (lanes 4-6). Importantly, free $\alpha \mathrm{Hb}$ and $\alpha \mathrm{Hb}-\mathrm{AHSP}$ complex were not detected in $A$ ssp ${ }^{-/-}$mice (lanes 7 and 8), and less $m \alpha_{2} \mathrm{~h} \beta_{2}$ heterotetramer genetic and biochemical evidence to prove this hypothesis.

Previously, we interbred mutant mice to show that $\beta$ thalassemia is exacerbated by loss of AHSP, indicating that one of its functions is to limit the damaging effects of excess free $\alpha \mathrm{Hb}(22)$. Supporting this model, structural studies demonstrated that AHSP converts oxygenated $\alpha \mathrm{Hb}$ to a bis-histidyl form in which the pro-oxidant activity of heme-bound iron is reduced through interactions with 2 different histidine residues of the $\alpha$-globin 

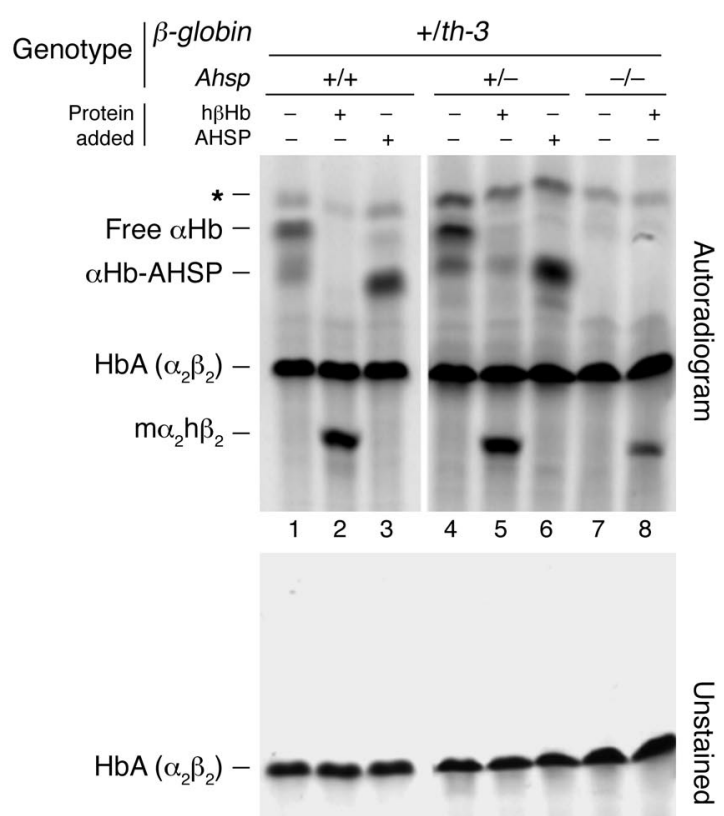

polypeptide, His87 and His58 $(21,23,43)$. Through this mechanism, excessive free $\alpha \mathrm{Hb}$ that is not incorporated into $\mathrm{HbA}$ is sequestered into a complex with AHSP and subsequently converted into a relatively inert form.

In the current study, we bred mice with Ahsp-null alleles onto an $\alpha$ thalassemic background to show that AHSP is also important for $\mathrm{Hb}$ homeostasis when $\alpha$-globin is not present in excess. In particular, Ahs $p^{-/-\alpha-g l o b i n}{ }^{*} \alpha / \alpha \alpha$ double-mutant mice showed worsened erythroid pathologies compared with mice with either mutation alone. These included greater anemia, abnormalities in erythrocyte morphology, and precipitation of both $\alpha$ - and $\beta$-globins. To explain these findings, we propose that AHSP acts as a molecular chaperone to stabilize newly synthesized $\alpha$-globin and facilitate its incorporation into HbA. According to this model, loss of AHSP destabilizes a fraction of nascent $\alpha$-globin, rendering it nonviable for $\mathrm{HbA}$ synthesis. This aggravates chain imbalance during concomitant $\alpha$ thalassemia because less $\alpha$-globin is available for binding to free $\beta$-globin. Consequently, $\beta$-globin precipitation increases, contributing to cellular damage.

In addition to abnormalities in mature erythrocytes, Ahsp ${ }^{-1-}$ $\alpha$-globin ${ }^{* \alpha / \alpha \alpha}$ mice exhibit increased ineffective erythropoiesis, most likely because there is greater accumulation and precipitation of free globin proteins in the double mutants. This is consistent with the general concept that increased levels of unstable free globin chains induce ineffective erythropoiesis in erythroid precursors (44, 45). Overall, the current study shows that AHSP is important in the context of mild, asymptomatic $\alpha$-globin deficiency. In the future, it will be interesting to analyze $A b s p^{-/-}$and $A b s p^{+/-}$mice with $2 \alpha$-globin genes deleted. Such studies will better establish the importance of AHSP in relation to the extent of globin chain imbalance.

Together, our past and current findings indicate that AHSP has at least 2 functions: to detoxify excess $\alpha \mathrm{Hb}$ and to act as a molecular chaperone that facilitates folding of newly formed $\alpha$ chains for assembly into $\mathrm{HbA}$ (Figure 7). The relative importance of each

\section{Figure 6}

Identification of transient free $\alpha \mathrm{Hb}$ and $\alpha \mathrm{Hb}$-AHSP complex in erythroid cells. Reticulocytes from $\beta$ thalassemia intermedia mice (strain th-3) with wild-type or mutant Ahsp alleles were pulse-labeled with ${ }^{35} \mathrm{~S}$-methionine for 10 minutes, lysed, and then treated with carbon monoxide to stabilize newly synthesized Hbs. Soluble proteins were fractionated by isoelectric focusing and visualized by autoradiography (top panel). Purified human $\beta \mathrm{Hb}(\mathrm{h} \beta \mathrm{Hb} ; 100 \mu \mathrm{g} / \mathrm{ml}$ ) or recombinant mouse AHSP $(500 \mu \mathrm{g} / \mathrm{ml})$ were added separately to different aliquots of each sample 30 minutes prior to electrophoresis, as indicated. The identities of the major bands are shown at the left. Free $\alpha \mathrm{Hb}$ (prominently visible in lanes 1 and 4) was observed at relatively high level in $\beta$ thalassemic mice and to a lesser extent in wild-type mice (data not shown); this band shifted to the position of a human-mouse $\mathrm{Hb}$ heterotetramer $\left(\mathrm{m}_{2} \mathrm{~h} \beta_{2}\right)$ upon addition of human $\beta \mathrm{Hb}$ (lanes 2 and 5 ) and to the position of a putative $\alpha \mathrm{Hb}$-AHSP complex upon addition of purified recombinant AHSP (lanes 3 and 6). Note that in Ahsp ${ }^{-1-}$ reticulocytes, the free $\alpha \mathrm{Hb}$ band was markedly reduced and the $\alpha \mathrm{Hb}$-AHSP band was absent (lanes 7 and 8 ). The identity of the slowest migrating band (asterisk) is unknown. The bottom panel shows the same unstained $\mathrm{CAE}$ membrane with steady-state $\mathrm{HbA}$ chains visible. Note that free $\alpha \mathrm{Hb}$ and $\alpha \mathrm{Hb}$-AHSP complex were not visualized, indicating that these species are relatively short-lived. function depends on the state of globin chain balance. One interesting question relates to how various conformational changes in $\alpha$-globin that are mediated by AHSP contribute to its different functions. For example, it is likely that formation of the oxidized bis-histidyl $\alpha \mathrm{Hb}$-AHSP complex is involved in detoxification of excess $\alpha \mathrm{Hb}$, particularly in $\beta$ thalassemia. In contrast, formation of this structure might be counterproductive to the role of AHSP as a molecular chaperone for HbA synthesis because the oxidized $\alpha \mathrm{Hb}$ must be enzymatically reduced at an energetic cost (43).

As a molecular chaperone for HbA synthesis, AHSP acts on at least 2 forms of $\alpha$-globin: the apo form, which lacks heme, and holo- $\alpha$-globin $(\alpha \mathrm{Hb})$. Apo- $\alpha$-globin is extremely unstable in solution and in cells. In vitro studies and analysis of globin mutations in patients demonstrate that heme insertion stabilizes the native structure of apo-globins (37, 46-48). Previous studies demonstrated that AHSP binds apo- $\alpha$-globin (32). Here we show that like heme, AHSP also promotes in vivo and in vitro apo- $\alpha$-globin folding into a native structure. This property could explain, at least in part, how AHSP enhances $\alpha$-globin expression in Escherichia coli and in nonerythroid eukaryotic cells $(19,49)$. In general, protein folding occurs sequentially through discrete structural intermediates that guide formation of the native protein (50). AHSP binds $\alpha \mathrm{Hb}$ at the last $2 \alpha$ helices, termed $G$ and $H$, which are distant from the heme-binding pocket (21). Presumably, AHSP recognizes a similar protein fold in apo- $\alpha$-globin. Studies of myoglobins indicate that a semifolded intermediate containing the $\mathrm{G}$ and $\mathrm{H}$ helices may represent an early step toward folding into a native structure in all apoglobins (51). By binding and stabilizing this region, AHSP could promote formation of $\alpha$-globin tertiary structure. Of note, AHSP does not appear to bind or stabilize $\beta$-globin (19). This is consistent with the considerable amino acid sequence variation between $\alpha$-and $\beta$-globin in their G-H helical folds.

Since AHSP and heme bind $\alpha$-globin at different sites, they probably synergize to stabilize the native structure. Accordingly, $\alpha$-glo- 


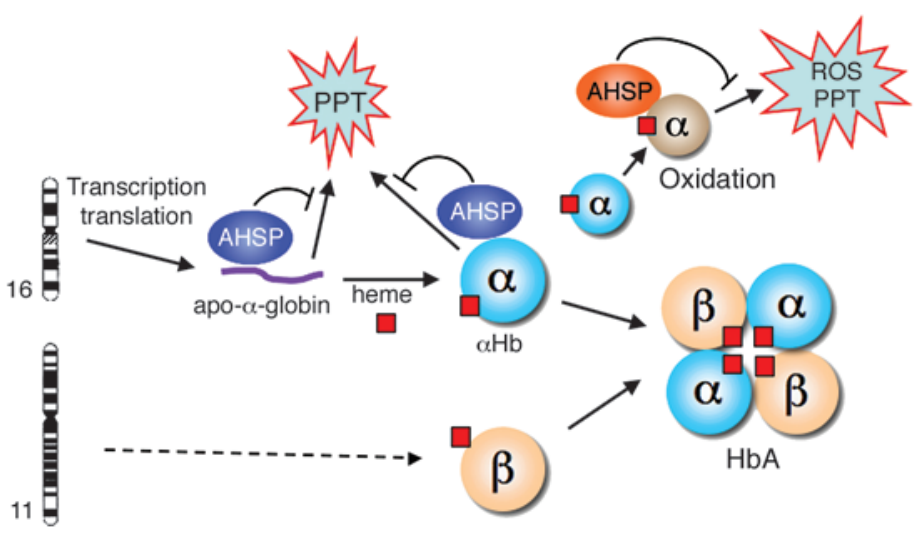

\section{Figure 7}

AHSP stabilizes multiple forms of $\alpha$-globin at different stages of $\mathrm{HbA}$ synthesis and homeostasis. Prior studies showed that AHSP (shown in red) inhibits ROS production and precipitation from excess $\alpha \mathrm{Hb}$ that accumulates in $\beta$ thalassemia. The current study demonstrates that AHSP (shown in blue) acts as a molecular chaperone to promote native folding and stability of apo- $\alpha$-globin and $\alpha \mathrm{Hb}$ en route to $\mathrm{HbA}$ synthesis. The brown circle indicates oxidized $\alpha \mathrm{Hb}$. bin bound to both heme and AHSP ( $\alpha$ Hb-AHSP) is more thermodynamically and chemically stable than free $\alpha \mathrm{Hb}$ alone $(19,21)$. Moreover, $\alpha \mathrm{Hb}$-AHSP can interact with $\beta \mathrm{Hb}$ to form $\mathrm{HbA}$ and free AHSP. In vivo, it is possible that AHSP stabilizes both the apo and heme-bound forms of $\alpha$-globin successively toward formation of HbA tetramers (Figure 7). These functions are well served by the high concentration of AHSP protein $(\sim 0.1 \mathrm{mM})$ in erythroid precursors undergoing active Hb synthesis (19). By contrast, the concentration of $\mathrm{HbA}$ tetramer in a mature erythrocyte is about $5 \mathrm{mM}$. The levels of various forms of free $\alpha$-globin in erythroid precursors are not known but presumably are much lower, as indicated in Figure 6. Therefore, sufficient AHSP is probably present during erythropoiesis to bind most or all nascent $\alpha$-globin before it interacts with heme and/or $\beta$-globin to form stable HbA. It is also possible that AHSP facilitates the assembly of monomeric $\alpha$ - and $\beta$-globin subunits into $\alpha \beta$ dimers, which is believed to be the rate-limiting step for HbA synthesis (52). In this case, loss of AHSP combined with reduced $\alpha$-globin dosage, which also slows monomer assembly, could impair this process to a point where individual unstable $\alpha$ and $\beta$ subunits are more prone to precipitate.

Our findings indicate that in erythroid cells AHSP stabilizes newly formed $\alpha$-globin transiently and then passes it off to $\beta \mathrm{Hb}$ to form $\mathrm{HbA}$. Analogous mechanisms in eukaryotes exist for other multisubunit proteins. For example, in B cells, Ig heavy chains are stabilized in the ER by the molecular chaperone BiP (53). Binding of light chains to heavy chains triggers BiP release to form mature Ig. However, compared with most chaperones, including BiP, AHSP recognizes a much more limited repertoire of "client" proteins. Specifically, AHSP recognizes a specific helix-loop-helix fold on a surface of $\alpha \mathrm{Hb}$ that normally binds $\beta$-globin. Indeed, $\alpha$-globin is the only known client protein for the molecular chaperone activities of AHSP. Similarly, single protein-specific molecular chaperones function in the assembly of tubulin $(54,55)$ and collagen $(56,57)$, multisubunit proteins that are produced at relatively high levels. One interesting open question is whether AHSP- $\alpha$-globin heterodimers form higher-order complexes with ubiquitously expressed chaperones that further facilitate $\alpha$-globin folding and/or degradation.

In mice, AHSP protects erythroid cells from the deleterious effects of both $\alpha$ - and $\beta$-globin deficiencies and from oxidant stress (22). The clinical significance of these findings for humans is not fully known. Mutations that ablate AHSP production or alter its protein structure are rare (refs. 58, 59, and M.J. Weiss et al., unpublished observations), but some reports indicate that reduced AHSP expression correlates with more severe thalassemic phenotypes (60,
61). One preliminary report suggests that reduced AHSP expression associated with specific gene haplotypes contributes to infection or drug-induced hemolytic anemia (62). In principle, it is also possible that stabilization of apo- $\alpha$-globin by AHSP becomes particularly important when heme availability for this function is limited, for example, during iron deficiency or genetic porphyrias. This potential function for AHSP would synergize with that of heme-regulated kinase (HRI), a cytosolic signaling protein that limits translation of apo-globins during heme-deficiency states (63). These possibilities can be investigated further by analyzing the effects of genetic porphyrias or iron deprivation in $A b s p^{-/-}$mice.

Our overall view is that by binding multiple forms of $\alpha$-globin, AHSP acts as a versatile homeostatic regulator to buffer against various imbalances and stresses that perturb Hb synthesis. Analogously, the chaperone heat-shock protein 90 (HSP90) can buffer against phenotypic manifestations of genetic variation in Drosophila and Arabidopsis $(64,65)$. Accordingly, it is possible that one evolutionary effect of AHSP is to increase tolerance to potentially deleterious globin mutations that confer resistance to malaria and environmental insults such as iron deficiency and oxidative stress.

\section{Methods}

Mice. Absp $p^{+/-}$mice were generated in our laboratory (19). $\alpha$ Thalassemia silent carrier mice (genotype $\alpha$-globin ${ }^{*} \alpha / \alpha$ ) were provided by Y. Kan (UCSF, San Francisco, California, USA) (24). $\beta$ Thalassemic mice (genotype $\beta$-glo$\mathrm{bin}^{+/ t h-3}$ ) were provided by Oliver Smithies (University of North Carolina, Chapel Hill, North Carolina, USA) (39). Mice were analyzed at age 3-6 months. The mice used were of mixed genetic background (129/C57BL/6). For the data shown in Table 1, littermates of various genotypes were analyzed to minimize any effects that might be due to their mixed genetic backgrounds. Animal protocols were approved by the Institutional Animal Care and Use Committee of The Children's Hospital of Philadelphia.

Hematology analysis. Blood was collected from the retro-orbital sinus or tail vein and then analyzed on a Bayer ADVIA 120 Hematology System. Photographs of blood smears were taken using a Axioskop 2 microscope with an Axiocam color digital camera (Zeiss).

Proteins. Recombinant AHSP proteins and purified $\mathrm{Hb}$ chains were prepared as described previously $(19,32)$. Apo- $\alpha$-globin ( $>95 \%$ heme-free) was prepared by high-performance liquid chromatography (Supplemental Figure 2A) (32). Apo- $\alpha$-globin was dissolved in $6 \mathrm{M} \mathrm{GdCl}$ overnight and then dialyzed against $0.5 \mathrm{M} \mathrm{GdCl}$. The concentration of apo- $\alpha$-globin was calculated using an extinction coefficient of $9.97 \mathrm{~cm}^{-1}$ at $280 \mathrm{~nm}$ (ProtParam tool; http://www.expasy.ch/tools/protparam.html). Oxygenated $\alpha \mathrm{Hb}$ concentration was calculated using an extinction coefficient of $13.5 \mathrm{~cm}^{-1}$ at $541 \mathrm{~nm}$. 
In aqueous buffer, apo- $\alpha$-globin tended to precipitate and also exhibited variable folding, as determined by $\mathrm{CD}$ (data not shown). In $0.5 \mathrm{M} \mathrm{GdCl}$, apo- $\alpha$-globin was more soluble and remained consistently denatured, while holo- $\alpha \mathrm{Hb}$ and AHSP retained their native helical structures under these conditions (Supplemental Figure 2, C and D). Therefore, proteinrefolding experiments were performed in $10 \mathrm{mM}$ sodium phosphate buffer (pH 7. 0) with $0.5 \mathrm{M} \mathrm{GdCl}$.

$C D$ spectropolarimetry. $\alpha$-Helical content was monitored using the JASCO J-810 CD system using a 1-mm-path-length cell. The temperature was maintained at $4^{\circ} \mathrm{C}$ using a water-jacketed cell holder. Spectra were collected over the wavelength range of $200 \mathrm{~nm}$ to $250 \mathrm{~nm}$ using a scanning speed of $20 \mathrm{~nm} / \mathrm{min}$ and a bandwidth of $1 \mathrm{~nm}$. GdCl produced excessive background signal at wavelengths less than $208 \mathrm{~nm}$; therefore, data obtained at these wavelengths are not shown. Spectra were analyzing using SigmaPlot software (version 10.0; Systat).

Analysis of membrane-associated and cytosolic erythrocyte globins. Equal numbers of erythrocytes (adjusted by hematocrit) were lysed with hypotonic buffer and washed 5 times (66). Cytosolic protein fractions were collected by pooling the supernatant and first 2 washes after cell lysis. Membrane skeleton fractions were prepared as described previously (66). Globin proteins were fractionated by TAU gel electrophoresis (67) and stained with Coomassie brilliant blue.

To analyze newly synthesized globin chains in reticulocytes, $20 \mu \mathrm{l}$ of freshly collected blood was washed in methionine- and cysteine-free medium (Iscove's Modified Dulbecco Medium [IMDM] Met ${ }^{-} \mathrm{Cys}^{-} \mathrm{Glu}^{-}$media, $2 \mathrm{mM}$ L-glutamine, $10 \%$ dialyzed FBS, and $0.1 \mathrm{mM}$ nonessential amino acids) and then incubated at $37^{\circ} \mathrm{C}$ for 1 hour in the same medium. ${ }^{35}$ S-labeled methionine/cysteine $(50 \mu \mathrm{Ci})$ was added for 15 minutes, then the cells were lysed and fractionated as described in the preceding paragraph. The entire radiolabeled membrane fraction and $5 \%$ of the cytosolic fraction for each sample were fractionated on TAU gels and analyzed by autoradiography. Phosphorimager (GE Healthcare) was used to quantify radiolabeled globins identified on the TAU gels. Cell culture reagents were obtained from Invitrogen or Cellgro (Mediatech Inc.).

Flow cytometry analysis. Flow cytometry was performed using a FACSCalibur System (BD Biosciences) and analyzed with CellQuest Pro software (version 5.1.1; BD Biosciences). Mouse spleens were disaggregated into single-cell suspensions and stained with PE-conjugated anti-Ter119, FITCconjugated anti-CD71, and 7-AAD as described previously (31). For detection of intracellular ROS, $2 \times 10^{6}$ peripheral blood cells were incubated with $25 \mu \mathrm{g} / \mathrm{ml}$ 2',7,-DCFH-DA (Sigma-Aldrich), and fluorescence emitted by oxidized DCF was detected on FACS channel FL-1.

In vitro synthesis of $\mathrm{HbA}$. In vitro $\mathrm{TNT}$ was performed using the wheat germ TNT kit (Promega) according to published protocols $(68,69)$. Plasmids containing human $\alpha$ - or $\beta$-globin cDNAs (pcDNA3- $\alpha$, T7 promoter or pcDNA3- $\beta$, Sp6 promoter) were added to the TNT mixture with $\mathrm{CN}$-hemin. After the reaction, purified human $\alpha \mathrm{Hb}$ or $\beta \mathrm{Hb}$ were added to complex with the newly synthesized radiolabeled globin chain. Additionally, purified unlabeled $\mathrm{HbA}$ was added to facilitate the formation and subsequent analysis of radiolabeled $\mathrm{HbA}$ tetramers $(68,69)$. HbA assembly was monitored by electrophoresis on Titan IIIH cellulose acetate membranes (Helena Laboratories) according to the manufacturer's instructions. After electrophoresis, the membranes were washed in 5\% acetic acid for 1 hour and subjected to autoradiography.

Limited proteolysis. $\alpha$-Globin was generated by TNT reaction and mixed with an equal volume of buffer containing $10 \mathrm{mM}$ Tris- $\mathrm{HCl} \mathrm{pH}$ 7.6, 100 $\mathrm{mM}$ potassium acetate, $10 \mathrm{mM}$ magnesium acetate, $1 \mathrm{mM}$ dithiothreitol, and $0.5 \mathrm{mM}$ cycloheximide. After addition of $10 \mu \mathrm{g} / \mathrm{ml}$ trypsin, aliquots were withdrawn at various time points, added to an equal volume of $95^{\circ} \mathrm{C}$ $2 \times$ SDS sample buffer (Sigma-Aldrich), and maintained at $95^{\circ} \mathrm{C}$ for 10 minutes in preparation for electrophoresis. Image analysis was performed using ImageJ software (version 1.34; http://rsb.info.nih.gov/ij/) and plotted using SigmaPlot software.

Isoelectric focusing of nascent reticulocyte proteins. Twenty microliters of freshly collected blood was incubated in methionine-free IMDM, $2 \mathrm{mM}$ L-glutamine, $10 \%$ dialyzed FBS, and $0.1 \mathrm{mM}$ nonessential amino acids at $37^{\circ} \mathrm{C}$ for 1 hour, then ${ }^{35} \mathrm{~S}$-labeled methionine was added for 10 minutes. Then the cells were washed with PBS and exposed to carbon monoxide to stabilize ferrous heme groups and inhibit their oxidation. The cells were lysed in water and clarified by centrifugation, and soluble fractions were loaded onto precast agarose gels (FR9120 Hemoglobin Test Kit; PH6-8; PerkinElmer). Electrophoresis was performed on an LKB 2117 Multiphor at 3,000 V for 50 minutes, and labeled proteins were analyzed by autoradiography.

Statistics. Data in Figure 3 and Table 1 were analyzed by 2 -tailed Student's $t$ test. A $P$ value of less than 0.05 was considered significant.

\section{Acknowledgments}

We thank Yuet Wei Kan and Judy Chang for providing $\alpha$ thalassemic mice. Kazuhiko Adachi and Yi Zhao provided technical advice and reagents for the wheat germ TNT reactions. Kelley Capobianchi assisted with hematology analysis. CD experiments were performed with the assistance of the protein core facility at The Children's Hospital of Philadelphia. We thank David Nathan, Gerd Blobel, and Yair Argon for comments on the manuscript. This work was funded by NIH grant R01 DK69692-01.

Received for publication January 30, 2007, and accepted in revised form April 24, 2007.

Address correspondence to: Mitchell J. Weiss, The Children's Hospital of Philadelphia, Room 316B, Abramson Research Building, 3615 Civic Center Blvd., Philadelphia, Pennsylvania 19104, USA. Phone: (215) 590-0565; Fax: (215) 590-4834; E-mail: weissmi@ email.chop.edu.
1. Dickerson, R.E., and Geis, I. 1983. Hemoglobin: structure, function, evolution, and pathology. Benjamin Cummings. Menlo Park, California, USA. 176 pp.

2. Fermi, G., and Perutz, M.F. 1981. Atlas of molecular structures in biology. Volume 2, Haemoglobin and myoglobin. Oxford University Press. Oxford, United Kingdom. Clarendon Press. New York, New York, USA. 104 pP.

3. Frydman, J. 2001. Folding of newly translated proteins in vivo: the role of molecular chaperones. Annu. Rev. Biochem. 70:603-647.

4. Forget, B.G., and Pearson, H.A. 1995. Hemoglobin synthesis and the thalassemias. In Blood: principles and practices of hematology. R.I. Handin, S.E. Lux, and T.P. Stossel, editors. J.B. Lippincott. Philadelphia, Pennsylvania, USA. 1525-1990.
5. Nathan, D.G., and Gunn, R.B. 1966. Thalassemia: the consequences of unbalanced hemoglobin synthesis. Am. J. Med. 41:815-830.

6. Bank, A. 1968. Hemoglobin synthesis in $\beta$-thalassemia: the properties of the free $\alpha$-chains. J. Clin. Invest. 47:860-866.

7. Baglioni, C. 1966. Chromosomal and cytoplasmic regulation of haemoglobin synthesis. Bibl. Haemat. 29:1056-1063.

8. Rachmilewitz, E., and Schrier, S.L. 2001. Pathophysiology of $\beta$ thalassemia. In Disorders of hemoglobin: genetics, pathophysiology and clinical management. M.H. Steinberg, B.G. Forget, D.R. Higgs, and R.L. Nagel, editors. Cambridge University Press. Cambridge, United Kingdom. 233-251.

9. Brunori, M., et al. 1975. Formation of superoxide in the autoxidation of the isolated $\alpha$ and $\beta$ chains of human hemoglobin and its involvement in hemichrome precipitation. Eur. J. Biochem. 53:99-104.

10. Bunn, H.F., and Forget, B.G. 1986. Hemoglobin function. In Hemoglobin: molecular, genetic and clinical aspects. H.F. Bunn and B.G. Forget, editors. Saunders. Philadelphia, Pennsylvania, USA. 37-60.

11. Shaeffer, J.R. 1967. Evidence for soluble alphachains as intermediates in hemoglobin synthesis in the rabbit reticulocyte. Biochem. Biophys. Res. Commun. 28:647-652.

12. Tavill, A.S., Grayzel, A.I., Vanderhoff, G.A., and London, I.M. 1967. The control of hemoglobin synthesis. Trans. Assoc. Am. Physicians. 80:305-313.

13. Olivieri, N.F., and Weatherall, D.J. 2001. Clinical aspects of beta thalassemia. In Disorders of hemoglo- 
bin: genetics, pathophysiology and clinical management. M.H. Steinberg, B.G. Forget, D.R. Higgs, and R.L. Nagel, editors. Cambridge University Press. Cambridge, United Kingdom. 277-341.

14. Bukau, B., Weissman, J., and Horwich, A. 2006. Molecular chaperones and protein quality control. Cell. 125:443-451.

15. Wickner, S., Maurizi, M.R., and Gottesman, S. 1999. Posttranslational quality control: folding, refolding, and degrading proteins. Science. 286: $1888-1893$.

16. Shaeffer, J.R., and Kania, M.A. 1995. Degradation of monoubiquitinated alpha-globin by $26 \mathrm{~S}$ proteasomes. Biochemistry. 34:4015-4021.

17. Shaeffer, J.R., and Cohen, R.E. 1998. Enhancement by ubiquitin aldehyde of proteolysis of hemoglobin alpha-subunits in beta-thalassemic hemolysates. Ann. N. Y. Acad. Sci. 850:394-397.

18. Shaeffer, J.R. 1983. Turnover of excess hemoglobin alpha chains in beta-thalassemic cells is ATPdependent. J. Biol. Chem. 258:13172-13177.

19. Kihm, A.J., et al. 2002. An abundant erythroid protein that stabilizes free alpha hemoglobin. Nature. 417:758-763.

20. Baudin-Creuza, V., et al. 2004. Transfer of human alpha- to beta-hemoglobin via its chaperone protein: evidence for a new state. J. Biol. Chem. 279:36530-36533.

21. Feng, L., et al. 2004. Molecular mechanism of AHSP-mediated stabilization of alpha-hemoglobin. Cell. 119:629-640.

22. Kong, Y., et al. 2004. Loss of $\alpha$-hemoglobin-stabilizing protein impairs erythropoiesis and exacerbates $\beta$-thalassemia. J. Clin. Invest. 114:1457-1466. doi:10.1172/JCI200421982.

23. Feng, L., et al. 2005. Structure of oxidized alphahaemoglobin bound to AHSP reveals a protective mechanism for haem. Nature. 435:697-701.

24. Chang, J., et al. 1996. Inactivation of mouse alpha-globin gene by homologous recombination: mouse model of hemoglobin $\mathrm{H}$ disease. Blood. 88:1846-1851.

25. Advani, R., et al. 1992. Characterization and comparison of the red blood cell membrane damage in severe human alpha- and beta-thalassemia. Blood. 79:1058-1063.

26. Joshi, W., Leb, L., Piotrowski, J., Fortier, N., and Snyder, L.M. 1983. Increased sensitivity of isolated alpha subunits of normal human hemoglobin to oxidative damage and crosslinkage with spectrin. J. Lab. Clin. Med. 102:46-52.

27. Rouyer-Fessard, P., et al. 1989. A study of membrane protein defects and alpha hemoglobin chains of red blood cells in human beta thalassemia. J. Biol. Chem. 264:19092-19098.

28. Schrier, S.L., Rachmilewitz, E., and Mohandas, N. 1989. Cellular and membrane properties of alpha and beta thalassemic erythrocytes are different: implication for differences in clinical manifestations. Blood. 74:2194-2202.

29. Shinar, E., Rachmilewitz, E.A., and Lux, S.E. 1989. Differing erythrocyte membrane skeletal protein defects in $\alpha$ and $\beta$ thalassemia. J. Clin. Invest. 83:404-410.

30. Shinar, E., Shalev, O., Rachmilewitz, E.A., and Schrier, S.L. 1987. Erythrocyte membrane skeleton abnormalities in severe beta-thalassemia. Blood. 70:158-164.

31. Liu, Y., et al. 2006. Suppression of Fas-FasL coexpression by erythropoietin mediates erythroblast expansion during the erythropoietic stress response in vivo. Blood. 108:123-133.

32. Gell, D., Kong, Y., Eaton, S.A., Weiss, M.J., and Mackay, J.P. 2002. Biophysical characterization of the alpha-globin binding protein alpha-hemoglobin stabilizing protein. J. Biol. Chem. 277:40602-40609.

33. Fedorov, A.N., and Baldwin, T.O. 1998. Protein folding and assembly in a cell-free expression system. Methods Enzymol. 290:1-17.

34. Frydman, J., Nimmesgern, E., Ohtsuka, K., and Hartl, F.U. 1994. Folding of nascent polypeptide chains in a high molecular mass assembly with molecular chaperones. Nature. 370:111-117.

35. Ascoli, F., Fanelli, M.R., and Antonini, E. 1981. Preparation and properties of apohemoglobin and reconstituted hemoglobins. Methods Enzymol. 76:72-87.

36. Hargrove, M.S., and Olson, J.S. 1996. The stability of holomyoglobin is determined by heme affinity. Biochemistry. 35:11310-11318.

37. Waks, M., Yip, Y.K., and Beychok, S. 1973. Influence of prosthetic groups on protein folding and subunit assembly. Recombination of separated human alpha- and beta-globin chains with heme and alloplex interactions of globin chains with heme-containing subunits. J. Biol. Chem. 248:6462-6470.

38. Santiveri, C.M., et al. 2004. NMR structure of the alpha-hemoglobin stabilizing protein: insights into conformational heterogeneity and binding. J. Biol. Chem. 279:34963-34970.

39. Yang, B., et al. 1995. A mouse model for beta 0-thalassemia. Proc. Natl. Acad. Sci. U. S. A. 92:11608-11612.

40. Weiss, M.J., et al. 2005. Role of alpha hemoglobinstabilizing protein in normal erythropoiesis and beta thalassemia. Ann. N. Y. Acad. Sci. 1054:103-117.

41. Huang, S.-C., and Benz, E.J. 2001. Posttranscriptional factors influencing the hemoglobin content of the red cell. In Disorders of hemoglobin: genetics, pathophysiology and clinical management. M.H. Steinberg, B.G. Forget, D.R. Higgs, and R.L. Nagel, editors. Cambridge University Press. Cambridge, United Kingdom. 146-173.

42. Luzzatto, L., and Notaro, R. 2002. Haemoglobin's chaperone. Nature. 417:703-705.

43. Zhou, S., Olson, J.S., Fabian, M., Weiss, M.J., and Gow, A.J. 2006. Biochemical fates of alpha hemoglobin bound to alpha hemoglobin-stabilizing protein AHSP. J. Biol. Chem. 281:32611-32618.

44. Fessas, P. 1963. Inclusions of hemoglobin erythroblasts and erythrocytes of thalassemia. Blood. 21:21-32.

45. Ranney, H.M. 2001. Hemoglobin: a historical perspective. In Disorders of hemoglobin: genetics, pathophysiology and clinical management. M.H. Steinberg, B.G. Forget, D.R. Higgs, and R.L. Nagel, editors. Cambridge University Press. Cambridge, United Kingdom. 1-24.

46. Dacie, J.V., Shinton, N.K., Gaffney, P.J., Jr., and Lehmann, H. 1967. Haemoglobin Hammersmith (beta-42 (CDI) Phe replaced by ser). Nature. 216:663-665

47. Wajcman, H., et al. 1992. Structure of the EF corner favors deamidation of asparaginyl residues in hemoglobin: the example of $\mathrm{Hb}$ La Roche-surYon [ $\beta 81$ (EF5) Leu $\rightarrow$ His]. Biochim. Biophys. Acta. 1138:127-132.

48. Yip, Y.K., Waks, M., and Beychok, S. 1972. Influence of prosthetic groups on protein folding and subunit assembly. I. Conformational differences between separated human alpha- and beta-globins. J. Biol. Chem. 247:7237-7244.

49. Vasseur-Godbillon, C., Hamdane, D., Marden, M.C., and Baudin-Creuza, V. 2006. High-yield expression in Escherichia coli of soluble human alpha-hemoglobin complexed with its molecular chaperone. Protein Eng. Des. Sel. 19:91-97.

50. Maity, H., Maity, M., Krishna, M.M., Mayne, L., and Englander, S.W. 2005. Protein folding: the stepwise assembly of foldon units. Proc. Natl. Acad. Sci. U. S. A. 102:4741-4746.
51. Musto, R., Bigotti, M.G., Travaglini-Allocatelli, C., Brunori, M., and Cutruzzola, F. 2004. Folding of Aplysia limacina apomyoglobin involves an intermediate in common with other evolutionarily distant globins. Biochemistry. 43:230-236.

52. Bunn, H.F. 1987. Subunit assembly of hemoglobin: an important determinant of hematologic phenotype. Blood. 69:1-6.

53. Vanhove, M., Usherwood, Y.K., and Hendershot, L.M. 2001. Unassembled Ig heavy chains do not cycle from $\mathrm{BiP}$ in vivo but require light chains to trigger their release. Immunity. 15:105-114.

54. Archer, J.E., Vega, L.R., and Solomon, F. 1995. $\mathrm{Rbl} 2 \mathrm{p}$, a yeast protein that binds to beta-tubulin and participates in microtubule function in vivo. Cell. 82:425-434.

55. Cowan, N.J., and Lewis, S.A. 2001. Type II chaperonins, prefoldin, and the tubulin-specific chaperones. Adv. Protein Chem. 59:73-104.

56. Nagai, N., et al. 2000. Embryonic lethality of molecular chaperone hsp47 knockout mice is associated with defects in collagen biosynthesis. J. Cell Biol. 150:1499-1506.

57. Tasab, M., Batten, M.R., and Bulleid, N.J. 2000. Hsp47: a molecular chaperone that interacts with and stabilizes correctly-folded procollagen. EMBOJ. 19:2204-2211.

58. Cappellini, M.D., Refaldi, C., Bignamini, D., Zanaboni, L., and Fiorelli, G. 2004. Molecular analysis of alpha hemoglobin stabilizing protein (AHSP) in Caucasian patients with different beta-thalassemia phenotypes [abstract]. Blood (ASH Annual Meeting Abstracts). 104:3770.

59. Viprakasit, V., et al. 2004. Evaluation of alpha hemoglobin stabilizing protein (AHSP) as a genetic modifier in patients with beta thalassemia. Blood. 103:3296-3299.

60. Galanello, R., Perseu, L., Giagu, N., and Sole, G. 2003. AHSP expression in beta-thalassemia carriers with thalassemia intermedia phenotype [abstract]. Blood (ASH Annual Meeting Abstracts). 102:1881a.

61. Lai, M.I., et al. 2006. Alpha-haemoglobin stabilising protein is a quantitative trait gene that modifies the phenotype of beta thalassemia. Br. J. Haematol. 133:675-682.

62. Kanno, H., et al. 2005. Alpha hemoglobin stabilizing protein (AHSP) is a susceptibility gene to drug/ infection-induced hemolytic anemia [abstract]. Blood (ASH Annual Meeting Abstracts). 106:479a.

63. Han, A.P., et al. 2001. Heme-regulated eIF2alpha kinase (HRI) is required for translational regulation and survival of erythroid precursors in iron deficiency. EMBO J. 20:6909-6918.

64. Queitsch, C., Sangster, T.A., and Lindquist, S. 2002. Hsp90 as a capacitor of phenotypic variation. Nature. 417:618-624.

65. Rutherford, S.L., and Lindquist, S. 1998 . Hsp90 as a capacitor for morphological evolution. Nature. 396:336-342.

66. Sorensen, S., Rubin, E., Polster, H., Mohandas, N., and Schrier, S. 1990. The role of membrane skeletal-associated alpha-globin in the pathophysiology of beta-thalassemia. Blood. 75:1333-1336.

67. Alter, B.P. 1981. Gel electrophoretic separation of globin chains. Prog. Clin. Biol. Res. 60:157-175.

68. Adachi, K., Zhao, Y., and Surrey, S. 2002. Assembly of human hemoglobin ( $\mathrm{Hb}$ ) beta- and gammaglobin chains expressed in a cell-free system with alpha-globin chains to form $\mathrm{Hb} \mathrm{A}$ and $\mathrm{Hb}$ F. J. Biol. Chem. 277:13415-13420.

69. Adachi, K., Zhao, Y., and Surrey, S. 2003. Effects of heme addition on formation of stable human globin chains and hemoglobin subunit assembly in a cell-free system. Arch. Biochem. Biophys. 413:99-106. 